\title{
Incêndios florestais no Amapá
}

\section{Doraci MiLANi}

\section{RESUMO}

Os incêndios florestais são responsáveis por grandes perdas tanto vegetais quanto animais e em sua maioria estão associados a práticas agrícolas.

A AMCEL - Amapá Florestal e Celulose S/A com uma área de 427.009 ha no estado do Amapá, possui uma estrutura de prevenção e combate a incêndios composta por caminhões pipa, torres de observação, entre outros. Dados mostram que o período de maior de incidência de incêndios no Hemisfério norte está compreendido entre os meses de Agosto a Novembro e o horário de maior incidência de ocorrências de incêndios nas áreas da AMCEL, nos anos de 1998 e 1999 é entre as 12:00 e 15:00 horas.

Palavras-Chave: Incêndios, Champion Amapá, Prevenção de incêndios

\section{INTRODUÇÃO}

A Champion Papel e Celulose Ltda iniciou suas atividades florestais no Brasil no final da década de 50 e a produção de celulose no inicio de 1960 . A Champion ampliou seus negócios no Brasil com atividades florestais no estado do Mato Grosso do Sul (1988), aquisição da AMCEL - Amapá Florestal e Celulose S/A (1995) e da INPACEL - Indústria de Papel Arapoti (1998).

Em 20 de Junho de 2000 a Champion uniu-se a International Paper da união criando a maior empresa mundial de papel e produtos florestais e líder global, com aproximadamente 117.000 funcionários, em mais de 360 unidades em 50 países ao redor do mundo.

A área florestal da empresa no Brasil soma a quantia de aproximadamente 605.000 ha, distribuídas nos estados de São Paulo, Mato Grosso do Sul, Paraná, Minas Gerais e Amapá. (fig. 1) 


\begin{tabular}{|c|c|c|c|}
\hline ESTADO & TOTAL & PLANTADA & $\begin{array}{c}\text { RESERVA } \\
\text { LEGAL }\end{array}$ \\
\hline São Paulo & & & 8.493 \\
& 43.977 & 30.325 & \\
\hline Mato Grosso do Sul & & & 19.598 \\
\hline Amapá (CHF) & 207.870 & 5.022 & 103.401 \\
\hline Amapá (Amcel) & 219.139 & 73.620 & 109.333 \\
\hline Paraná & 50.847 & 29.846 & 14.964 \\
\hline Minas Gerais & 503 & 402 & 101 \\
\hline TOTAL & 605.043 & & 194.885 \\
\hline
\end{tabular}

Fig. 1:- Áreas florestais da Champion Papel e Celulose Ltda, no Brasil (Posição: 31/08/2000).

Como suporte para a área operacional e responsável pelo desenvolvimento de novas tecnologias foi criado em 1994 o CENTRO CHAMPION DE TECNOLOGIA FLORESTAL, com os seguintes departamentos:

- MELHORAMENTO ClÁSSICO E CLONAGEM DE Pinus spp

Responsável pelo desenvolvimento das estratégias de melhoramento florestal clássico e clonagem das florestas de pinus da empresa, nos estados do Paraná, Amapá e Mato Grosso do Sul. Responsável pela administração e condução do pomar de sementes de pinus da empresa em Morada Nova de Minas;

- SOLOS E MANEJO FLORESTAL - Pinus spp

Responsável pelo desenvolvimento de estratégias de conservação de solos e manejo florestal para todas as áreas de pinus plantadas na empresa nos estados do Paraná e Amapá;

- RECURSOS GENÉTICOS COMERCIAIS E MARCADORES MOLECULARES

Responsável pelo reconhecimento e determinação de todos os materiais genéticos - com base em eucalipto - a serem plantados na empresa para fins de experimentação e produção comercial, nos estados de São Paulo, Mato Grosso do Sul e Amapá; 
Responsável pelo desenvolvimento das estratégias de melhoramento florestal de eucalipto nos estados de São Paulo, Mato Grosso do Sul e Amapá;

- SOLOS E MANEJO FLORESTAL - Eucalyptus spp

Responsável pelo desenvolvimento de estratégias de conservação de solos e manejo florestal para todas as áreas de eucalipto plantadas na empresa, nos estados de São Paulo, Amapá e Mato Grosso do Sul;

\section{- TeCNOlogia DE PRODUÇÃO E PROPAGAÇÃO DE MATERIAIS GENÉTICOS}

Responsável pelo desenvolvimento da produção comercial de novos clones recomendados nos estados de São Paulo, Amapá e Mato Grosso do Sul. Também responsável pela administração do Laboratório de Biotecnologia em São Paulo;

\section{- PROTEÇÃO FLORESTAL}

Criado em Setembro de 1995 é responsável pela garantia do desenvolvimento saudável - através de pesquisas e controle de pragas e doenças - de todas as florestas da empresa nos estados do Paraná, São Paulo, Mato Grosso do Sul e Amapá. Responsável também por pesquisas de novas tecnologias para prevenção e combate a incêndios florestais.

\section{OS INCÊNDIOS FLORESTAIS}

As queimadas no Brasil têm sido objeto de preocupação e polêmica. Eles destroem os mais diversos sistemas ecológicos e tipos de agricultura, gerando impactos ambientais em escala local e regional.

O uso das queimadas tem os mais variados objetivos como: Método de gestão das pastagens; Eliminação de ectoparasitos do rebanho (carrapatos, por exemplo); Renovar a pastagem nativa, eliminando plantas invasoras e melhorando a digestibilidade da forragem durante o período seco; Eliminar troncos, galhos, etc após desmatamento de florestas; Limpeza de beiras de estradas, pré-colheita (cana de açúcar) e queima de restos de colheitas.

Nas atividades descritas acima, quando o fogo foge do controle, se alastram e são responsáveis por incêndios de grandes proporções como o ocorrido no estado de Roraima em 1998. 
Trabalhos realizados pela EMBRAPA Monitoramento por Satélite, estudando dados de 1991 a 1999, mostra que o número de queimadas segue com tendência de crescimento anual, tanto em termos espaciais, como em intensidade. Na Bacia Amazônica, o índice de incidência de queimadas passou de 4,4 em 1997 para 7,5 em 1999, por quadrícula de $100 \mathrm{Km}^{2}$.

No estado do Amapá as evoluções das queimadas são apresentadas pelo monitoramento orbital de queimadas, realizado pela EMBRAPAMonitoramento por Satélite, através de imagens do satélite NOAA e estão representados na figura 2 .

Fig. 2:- Mapas de ocorrência de queimadas no estado do Amapá por quadrícula de $100 \mathrm{Km}^{2}$ no período de 1993 a 2000.
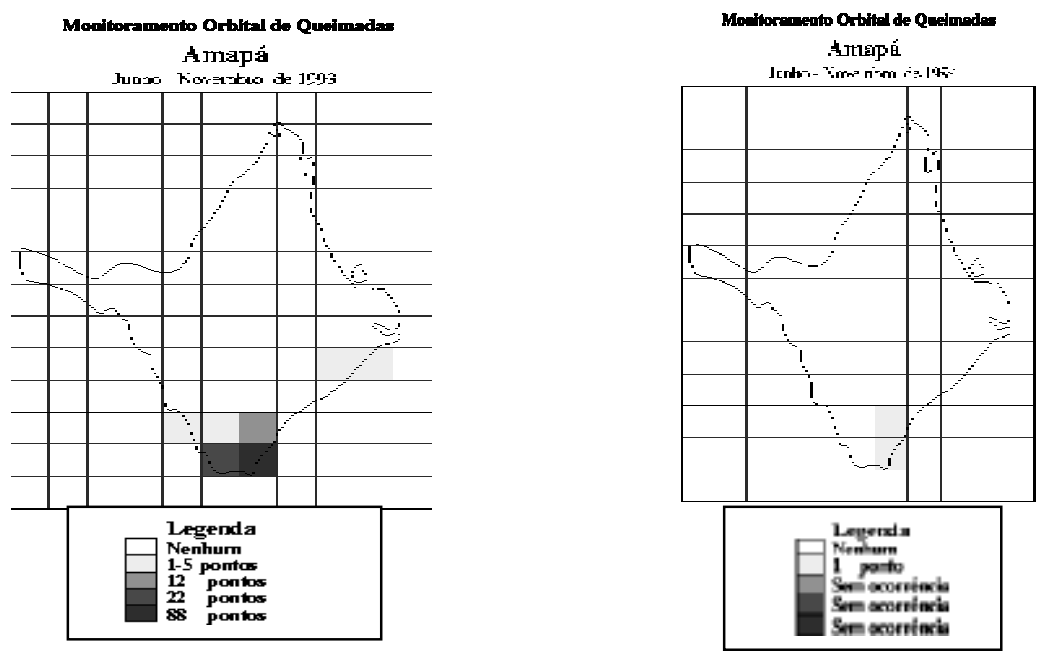


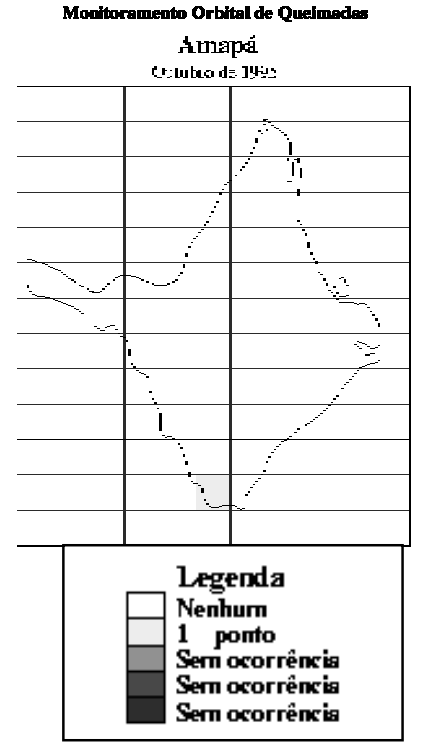

Monltoramento Orbital de Queimadas 4 mapaz

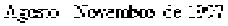

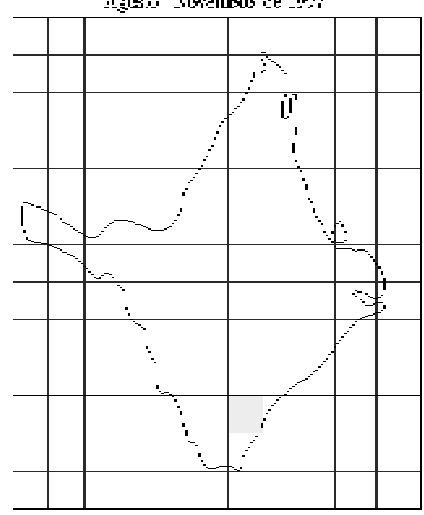

Monitoramento Orbital de Qutimadas

Amapá

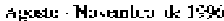

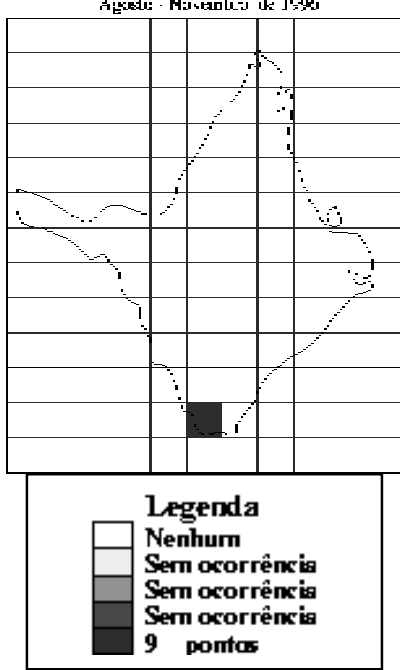

Mon'toramento Orbital de Queimades

Amapá

hais - Yruentro de jocg

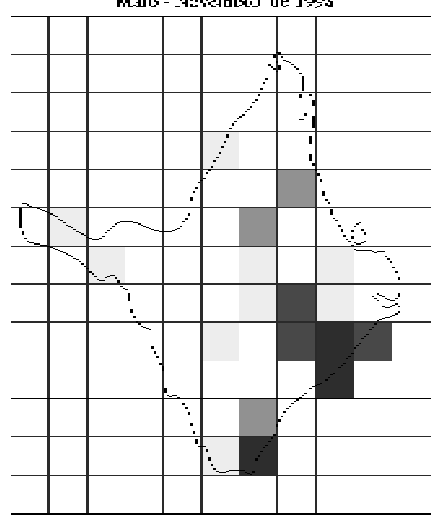


Monitoramento Orbital de Queimades

Amapá

Julbo - Nowernbuo de 1909

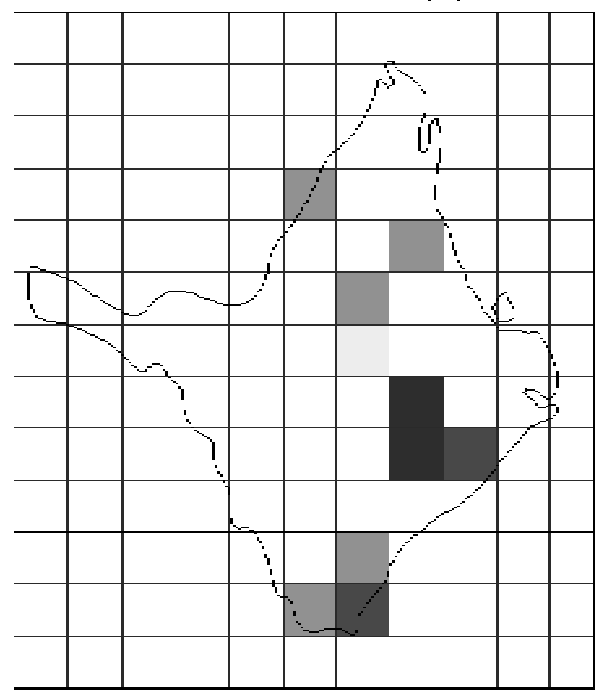

Legenda

Nenhum

1 ponto

2-3 pontos

5-6 pontas

11-12 pontos
Monitoramento Orbital de Queimadas

Amapá

Agosto de 2000

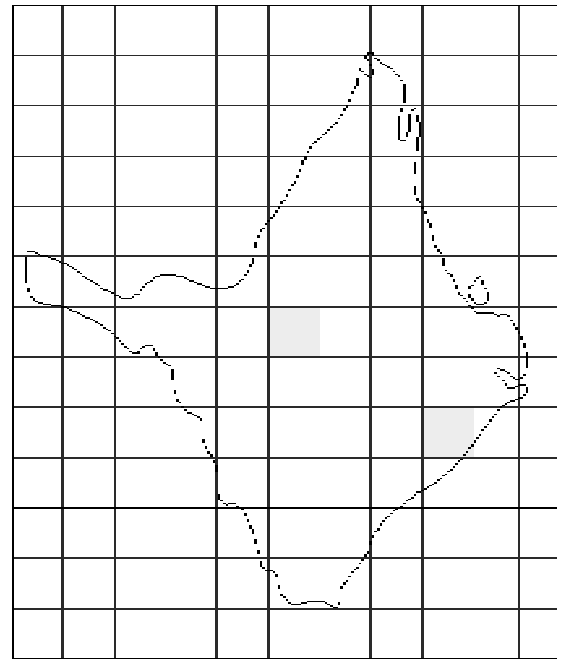




\section{CHAMPION NO AMAPÁ}

A Champion iniciou suas atividades no estado do Amapá no ano de 1995 e conta com uma área de 427.009 ha, dos quais 78.642 ha plantados.

Os Hortos florestais da Amcel estão localizados nos municípios de Macapá, Santana, Porto Grande, Ferreira Gomes, Tartarugalzinho, Pracuúba e Amapá figura 3.

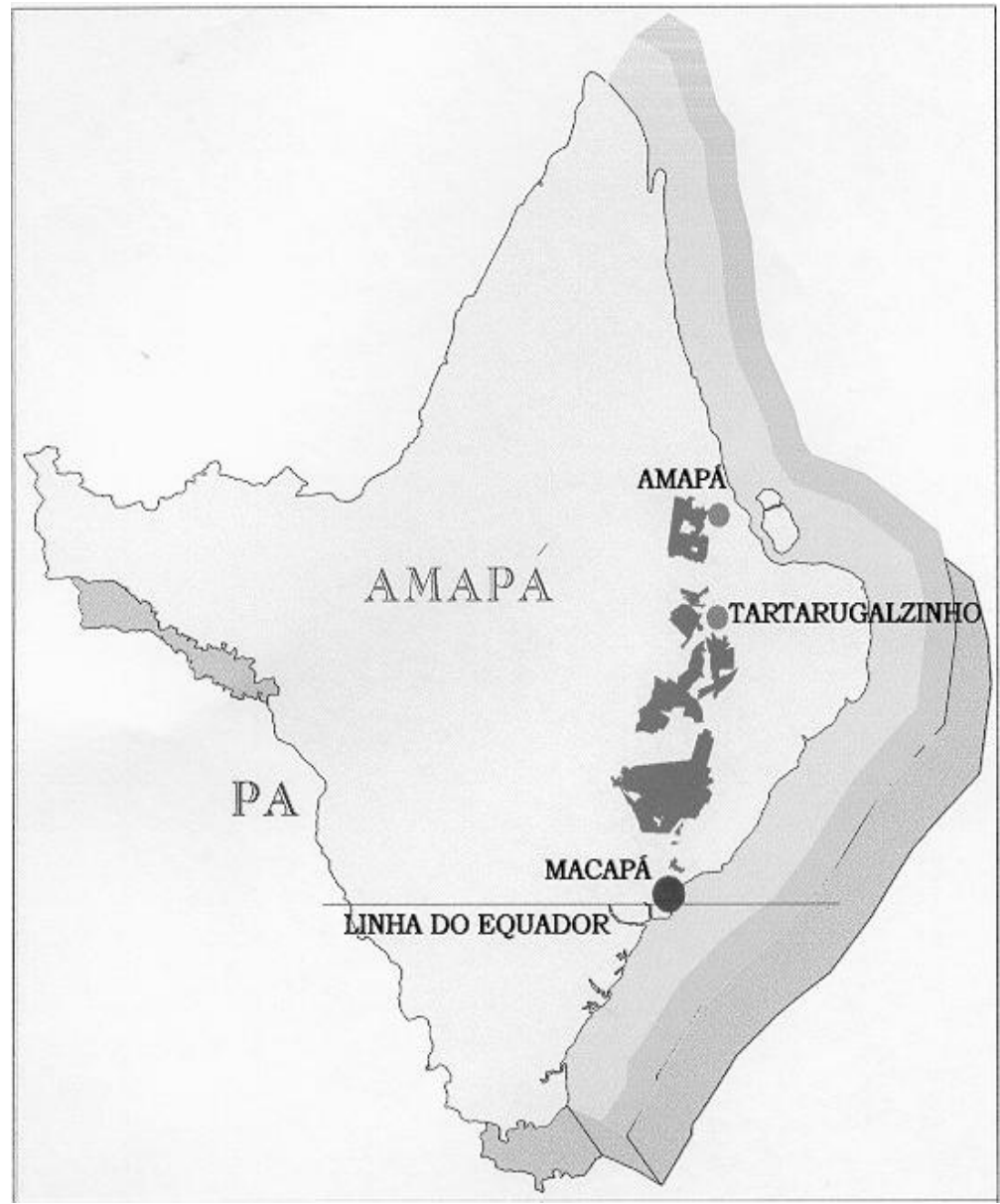


Fig. 3:- Mapa com localização das áreas da Amcel - AP

CARACTERIZAÇÃO CLIMÁTICA

Temperatura média atual

$27^{\circ} \mathrm{C}$

Temperatura média mínima

$23^{\circ} \mathrm{C}$

Temperatura média máxima

$33^{\circ} \mathrm{C}$

Precipitação média anual

$2.100 \mathrm{~mm}$

Precipitação mínima anual

$1.500 \mathrm{~mm}$

Precipitação máxima anual

Déficit hídrico

$2.900 \mathrm{~mm}$

$403 \mathrm{~mm}$

\section{ESTRATÉGIA DE PREVENÇÃO E COMBATE A INCÊNDIOS NO AMAPÁ}

\section{OBJETIVO:}

A presente estratégia tem por objetivo principal normatizar procedimentos de

Prevenção e combate a incêndios florestais nas áreas da AMCEL e áreas vizinhas que possam oferecer algum risco.

\section{PREVENÇÕES:}

- Aceiros:

Todos os aceiros de divisa devem ser patrolados, de forma a dar acesso aos veículos em todos os carreadores de divisa, reduzindo também a possibilidade de passagem de fogo de áreas vizinhas às áreas da Amcel. Esta operação deverá ser realizada com uma largura de aproximadamente sete metros.

Em alguns casos, em locais de maior risco de incêndios, deve-se fazer a gradagem na lateral dos carreadores para diminuir o volume de material combustível e com isso o risco de incêndio. (Estes locais deverão ser definidos em função do histórico das ocorrências de incêndios nas áreas e volumes de materiais combustíveis existentes).

Além das divisas, os contornos das áreas que margeiam rios e rodovias públicas, também deverão ser limpos a partir do início do mês de Agosto. Esta operação será orientada por mapas que indicarão as áreas prioritárias de aceiros, com maiores riscos de incêndios.

- Alerta à Comunidade: 
No início do período de verão (período crítico de incêndios) é enviada a todos os vizinhos uma carta alertando sobre o período de incidência de incêndios e divulgando os telefones e locais que deverão ser acionados em caso de qualquer problema que venha ocorrer

Localização dos caminhões:

Os motoristas dos 3 (três) caminhões pipas de nossa frota deverão estar sempre alertas para qualquer chamado, portanto, estes caminhões nunca devem permanecer nas áreas sem motorista.

Os pontos que os caminhões permanecem são as frentes de trabalhos e um destes veículos sempre deverá estar na Oficina do $\mathrm{Km} \mathrm{78}$, por estar localizada em uma área mais central para combater focos localizados a margem direita do Rio Pedreira até os limites da área 20 (Porto Grande / Ferreira Gomes).

- Equipamentos dos caminhões:

É de responsabilidade dos motoristas manter todo o equipamento de combate a incêndios funcionando, assim como alguns equipamentos básicos, conforme segue:

Equipamentos que sempre devem acompanhar os caminhões pipas

10 abafadores, 2 enxadas, 1 pá, 2 machados, 4 rastelos, 2 foices, 1 pinga fogo, 1 pasta de mapas, com localização das tomadas d'água, 2 bombas costais e 1 facão.

- Abastecimentos dos caminhões:

Os caminhões devem estar sempre com os tanques de combustível e de água cheios.

Manutenções dos caminhões:

As manutenções preventivas nos veículos de combate a incêndios, no período crítico (Verão), deverão ser feitas a cada 3 (três) dias e não semanalmente como é de rotina.

Ferramentas:

Além das ferramentas e equipamentos básicos para um combate inicial, disponíveis nos caminhões pipas. Alguns pontos pré-determinados nas áreas deverão estar com ferramentas preparadas para acompanhar as turmas nos combates. Estes pontos deverão ser:

1. Ônibus da frente de plantio;

2. Ônibus da equipe de combate anual de formigas;

3. Ônibus da equipe de capina química.

Nestes veículos de transporte de pessoal, nos horários que os mesmos estão nas frentes de trabalho, deverá conter os seguintes equipamentos: 40 abafadores, 5 enxadas, 2 pás, 1 machado, 5 rastelos, 5 foices e 3 facões. 
Obs.: Estes equipamentos deverão estar sempre nas frentes de trabalhos e quando o veículo retornar nos finais de tarde, os equipamentos deverão ser mantidos nos ônibus em Porto Grande. O ônibus do turno noturno também deverá manter disponíveis esses equipamentos.

Os encarregados devem saber onde os ônibus pernoitam, assim como as residências dos motoristas, para o caso de haver necessidade de combate a incêndio durante a noite.

- Torres de Observação:

A AMCEL possui oito torres para observação de focos de incêndio e seu funcionamento inicia-se no final do inverno, quando os volumes de chuva diminuem e os riscos de incêndio aumentam. Este período é definido pela equipe técnica da empresa.

- Equipamentos necessários nas torres:

GONIÔMETROS:

Os goniômetros deverão ser aferidos no início dos trabalhos, conferindo as posições com o mapa geral da área do escritório central de Porto Grande.

\section{BINÓCULOS:}

Todas as torres deverão estar equipadas de binóculo e os operadores deverão estar treinados para usá-los de forma correta.

\section{RÁDIOS:}

As torres deverão Ter rádios e estes estarem em perfeitas condições de uso e seus operadores deverão se comunicar constantemente, informando possíveis fumaças nas redondezas, mantendo com isso alerta todos os veículos e a central.

\section{O PROCEDIMENTO A SER USADO PELOS TORRISTAS DEVE SER O SEGUINTE:}

De hora em hora, os torristas deverão passar para a torre de número seguinte, uma mensagem sobre as condições atuais do seu campo de ação.

\section{CONDUTA PARA CHECAGEM DAS OCORRÊNCIAS:}

Quando for observada, por uma das torres, uma fumaça que possa estar dentro da área da Amcel ou suspeitar que ofereça perigo às áreas, o torrista deve avisar a Central e comunicar outra torre, a mais próxima da direção da fumaça, para esta também observar o ponto exato da fumaça e passar os rumos dos Goniômetros para se fazer à triangulação e confirmar o real risco do foco. 
Caso haja risco, o responsável do Escritório Central (Porto Grande) deverá passar a área e o talhão exato da fumaça e esta deverá ser checada "in loco", por um veículo ágil (veículos leves). As informações deste local deverão ser passadas para o veículo mais próximo da área, já que no mapa geral da central terá as posições aproximadas de cada veículo nas áreas.

Se não houver risco, o responsável da Central passará a posição aproximada e orientará o torrista que a fumaça observada não oferece perigo às nossas áreas.

Caso haja dúvida na posição da fumaça, acionar uma terceira torre para a confirmação da posição do fogo.

\section{- COMBATE AOS INCÊNDIOS:}

No momento da checagem do local, observado pelo torrista, a pessoa que identificou primeiro o local do fogo (in loco), deverá avaliar rapidamente a situação e pedir reforços, avisando a central à localização exata do foco, dimensão aproximada, tipo de vegetação que está sendo queimada, possíveis riscos de aumentar, se está dentro da área ou fora, etc.

\section{- RÁDIOS DE COMUNICAÇÃO:}

Em momentos de incêndios ou alertas, os rádios deverão ser usados exclusivamente para comunicação do incêndio, ou seja, INCÊNDIO É PRIORIDADE ABSOLUTA.

- Procedimentos após os combates:

\section{RESCALDO:}

Concluído o combate do incêndio, o responsável da área de proteção florestal, deverá circular as frentes do fogo ocorrido e nessa avaliação, caso haja necessidade, deverá destacar alguns funcionários e caminhão pipa para fazer o rescaldo.

\section{RELATÓRIO DA OCORRÊNCIA:}

É de responsabilidade do técnico de proteção florestal o preenchimento do relatório de sinistros ocorridos e encaminhar para o conhecimento da Gerência Geral Florestal e arquivo na central.

\section{OCORRÊNCIA POLICIAL:}

O responsável da área deverá também fazer a ocorrência policial do incêndio. 


\section{OCORRÊNCIA DE INCÊNDIOS FLORESTAIS NAS ÁREAS DA AMCEL-AP.}

As ocorrências de incêndios nas áreas da Amcel estão representadas nos gráficos a seguir:

Gráfico 1 :Total de Área Queimada (ha) por Ano no Amapá (19989)

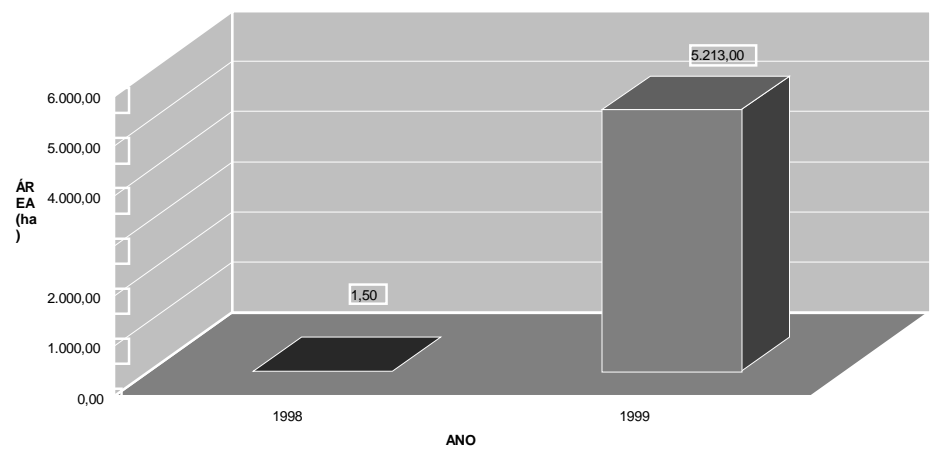

Gráfico 2 :Total de Área Queimada (ha) por Espécie no Amapá (189 1999)

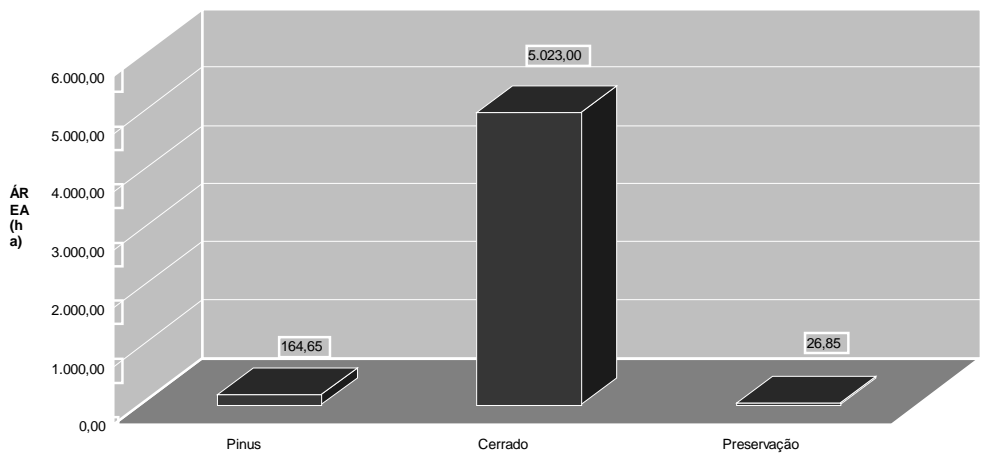


Gráfico 3 : Precipitação, Umidade Relativa,Temperatura médiareáQueimada
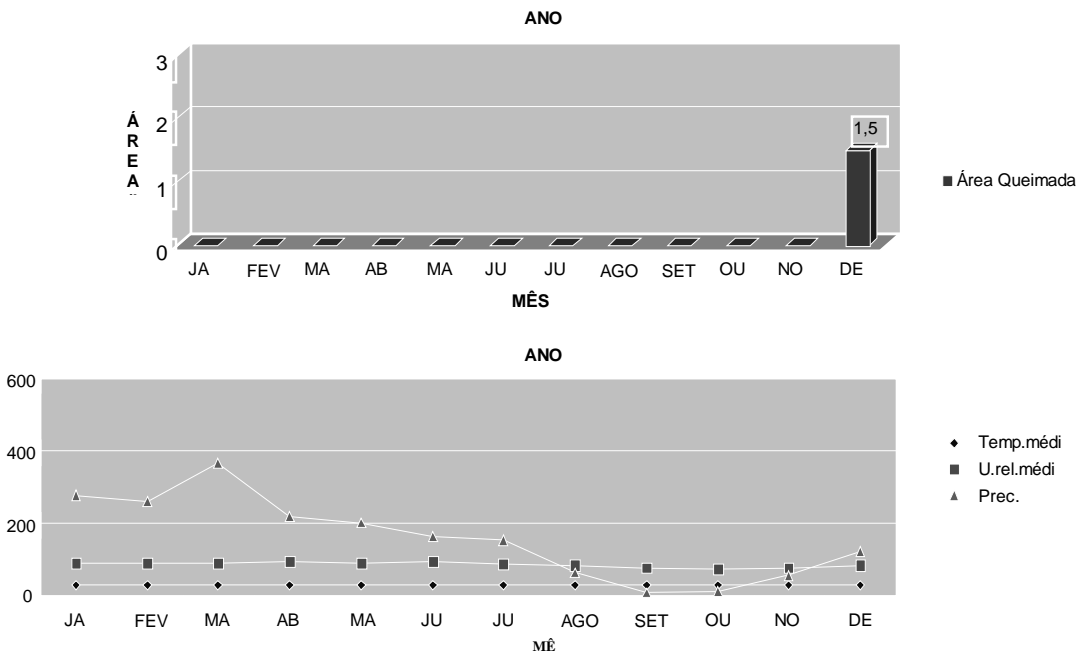

- Temp.médi

- U.rel.médi

$\triangle$ Prec.

Gráfico 5 :Horário/ $\mathbf{N}^{\circ}$ de Ocorrência no Período de 1998 Á 1999 - Amapá
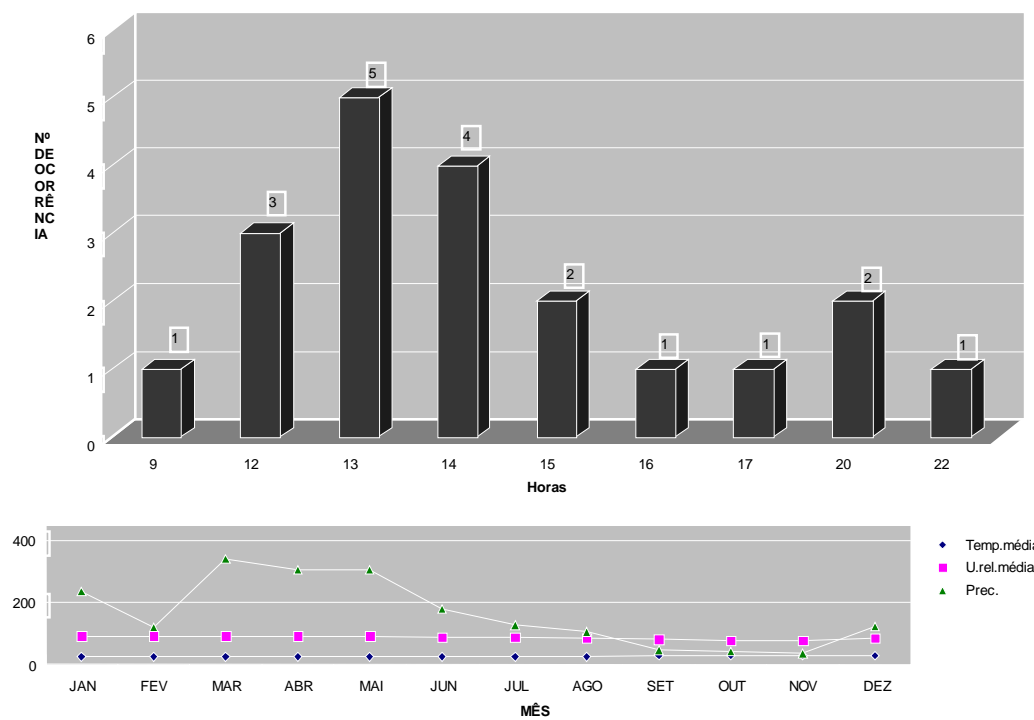

- Temp.média

- U.rel.média

4 Prec. 


\section{CONSIDERAÇÕES FINAIS}

- O período mais crítico para ocorrência de incêndios no hemisfério norte é entre os meses de Agosto a Novembro;

- $\quad 95 \%$ das queimadas ocorridas no estado do Amapá são decorrentes de práticas agrícolas;

- Os anos de 1998 e 1999 foram os anos com maior ocorrência de queimadas no estado do Amapá, durante o período de 1993 a Agosto de 2000;

- O horário de maior incidência de incêndios nas áreas da AMCEL, nos anos de 1998 e 1999 está compreendido entre as 12: e 15: horas.

\section{BIBLIOGRAFIA CITADA}

EMBRAPA MONITORAMENTO POR SATÉLITE. Monitoramento orbital por satélite. www.cnpm.embrapa.br

VITTI, A. N. Estratégia para prevenção e combate a incêndios florestais. Porto Grande, AMCEL, 2000. 